\title{
Inappropriate prescribing of combination inhalers in Northern Ireland: retrospective cross-sectional cohort study of prescribing practice in primary care
}

\author{
Joan Sweeney ${ }^{1}$, Chris C Patterson², Stephen O’Neill ${ }^{3}$, Ciaran O’Neill ${ }^{3}$, Gillian Plant ${ }^{4}$, \\ Veranne Lynch ${ }^{4}$, Teresa McAllister ${ }^{4}$, *Liam G Heaney ${ }^{1}$
}

1 Centre for Infection and Immunity, Queen's University of Belfast, Belfast, UK
${ }^{2}$ Centre for Public Health, Queen's University of Belfast, Belfast, UK
${ }^{3}$ School of Business and Economics, National University of Ireland, Galway, UK
${ }^{4}$ Medicines Management Team, Health and Social Care Board, Belfast, UK

Originally received 26th March 2013; resubmitted 6th June 2013; revised 21st August 2013; further revision 20th November 2013; accepted 17th December 2013; online 25th February 2014

\begin{abstract}
Background: Asthma management guidelines advocate a stepwise approach to asthma therapy, including the addition of a long-acting bronchodilator to inhaled steroid therapy at step 3. This is almost exclusively prescribed as inhaled combination therapy.

Aims: To examine whether asthma prescribing practice for inhaled combination therapy (inhaled corticosteroid/long-acting $\beta_{2}$-agonist (ICS/LABA)) in primary care in Northern Ireland is in line with national asthma management guidelines.

Methods: Using data from the Northern Ireland Enhanced Prescribing Database, we examined initiation of ICS/LABA in subjects aged 5-35 years in 2010.

Results: A total of 2,640 subjects (67\%) had no inhaled corticosteroid monotherapy (ICS) in the study year or six months of the preceding year (lead-in period) and, extending this to a 12-month lead-in period, 52\% had no prior ICS. $41 \%$ of first prescriptions for ICS/LABA were dispensed in January to March. Prior to ICS/LABA prescription, in the previous six months only $17 \%$ had a short-acting $\beta_{2}$-agonist (SABA) dispensed, $5 \%$ received oral steroids, and $17 \%$ received an antibiotic.

Conclusions: ICS/LABA therapy was initiated in the majority of young subjects with asthma without prior inhaled steroid therapy. Most prescriptions were initiated in the January to March period. However, the prescribing of ICS/LABA did not appear to be driven by asthma symptoms (17\% received SABA in the previous 6 months) or severe asthma exacerbation (only 5\% received oral steroids). Significant reductions in ICS/LABA, with associated cost savings, would occur if the asthma prescribing guidelines were followed in primary care.

(C) 2014 Primary Care Respiratory Society UK. All rights reserved.

J Sweeney et al. Prim Care Respir J 2014; 23(1): 74-78

http://dx.doi.org/10.4104/pcrj.2014.00007
\end{abstract}

Keywords asthma, asthma in primary care, asthma guidelines

\section{Introduction}

Asthma management guidelines recommend a stepwise approach to anti-inflammatory therapy, including the addition of a long-acting $\beta_{2}$-agonist (LABA) to inhaled corticosteroid therapy (ICS) at step 3 of the BTS/SIGN asthma management guidelines. ${ }^{1}$ This is almost exclusively prescribed as inhaled combination therapy (ICS/LABA). Inhaled corticosteroid therapy should be commenced at the lowest dose appropriate to the severity of the disease, and LABA should be added to ICS (in combination) only if asthma control has not been achieved with inhaled steroid monotherapy. ${ }^{1}$ If a decision to commence ICS/LABA is determined to be appropriate, the National Institute for Health and Care Excellence (NICE) recommends that the least costly device should be selected. ${ }^{2}$

However, prescribing practices do not always correspond to asthma management guidelines, and prescribing of ICS/LABA comes with a significant cost to the National Health Service (NHS). In

\footnotetext{
* Corresponding author: Professor Liam Heaney, Centre for Infection and Immunity, Queen's University of Belfast, Level 8, Belfast City Hospital, Lisburn Road, Belfast BT9 7AB, UK. Tel: +44 2890975850 Fax: +44 2890263879 E-mail: I.heaney@qub.ac.uk
} 
Northern Ireland alone, in 2010, f49 million was spent on respiratory drugs, with ICS/LABA accounting for $47 \%$ of this total. ${ }^{3}$ This large spend is not unique to Northern Ireland, as individual branded ICS/LABA inhalers account for two or three of the top five most costly drugs to the NHS across all regions of the UK. ${ }^{4-6}$ For example, in England, fluticasone/salmeterol 250 Evohaler has ranked as the most expensive drug in recent years with a spend of over $f 170$ million in 2011 and formoterol/budesonide 200/6 $\mu \mathrm{g}$ costing $£ 88$ million. ${ }^{4}$ Taking into consideration that there are substantial cost implications with prescribing ICS/LABA, it is imperative that such inhalers are prescribed appropriately in line with guidelines. With this in mind, we examined prescribing patterns for the initiation of combination inhalers in young patients with asthma in primary care in Northern Ireland.

\section{Methods}

We sought to investigate prescribing practice in patients aged 5-35 years who had a new prescription of ICS/LABA dispensed in 2010 using the Health and Social Care (HSC) Business Services Organisations, Enhanced Prescribing Database (EPD).

This database contains retrospective information on drugs prescribed and subsequently dispensed in primary care in Northern Ireland. A unique barcode is scanned from all paper prescriptions issued, which links the patient's Health and Care Number (HCN) with the details of their prescriptions. Practices that met the criteria of a $85-90 \%$ scan rate were included in the analysis (85-90\% of prescriptions being linked to a valid $\mathrm{HCN}$ ). The database stores details such as drug name as per British National Formulary (BNF) code, quantity, strength, and date of dispensing. Prescription data were anonymised with no patient identifiable information available to the investigators. As we did not have access to practice information for each prescription, we were unable to allow for intrapractice correlation effects in the dataset.

We identified all patients aged 5-35 years who had two or more prescriptions dispensed from any respiratory drug group from BNF categories 3.1, 3.2 or 3.3, and had a new prescription of ICS/LABA (Symbicort, Seretide, Fostair) dispensed in the period from January 2010 to December 2010. We chose to use two or more prescriptions as this would identify patients with persistent respiratory symptoms in this age group who might realistically progress to ICS/LABA.

We chose the age range 5-35 years specifically to remove the confounding diagnostic issue of chronic obstructive pulmonary disease in older patients. While we did not have access to individual diagnostic details on each of the prescriptions, it was felt reasonable to assume that the substantial majority of this population received ICS/LABA for a presumptive diagnosis of asthma, which is the only licensed indication in this age group. We accept that a small number may have had other airways diseases such as cystic fibrosis or bronchiectasis, but we believe that this number was likely to be small.

A total of 236 GP practices (65\% of all practices) were included. The total number of patients aged 5-35 years registered in these practices in January 2010 and remaining registered for the entire
Figure 1. Time intervals for examination of Enhanced Prescribing Database (EPD) data

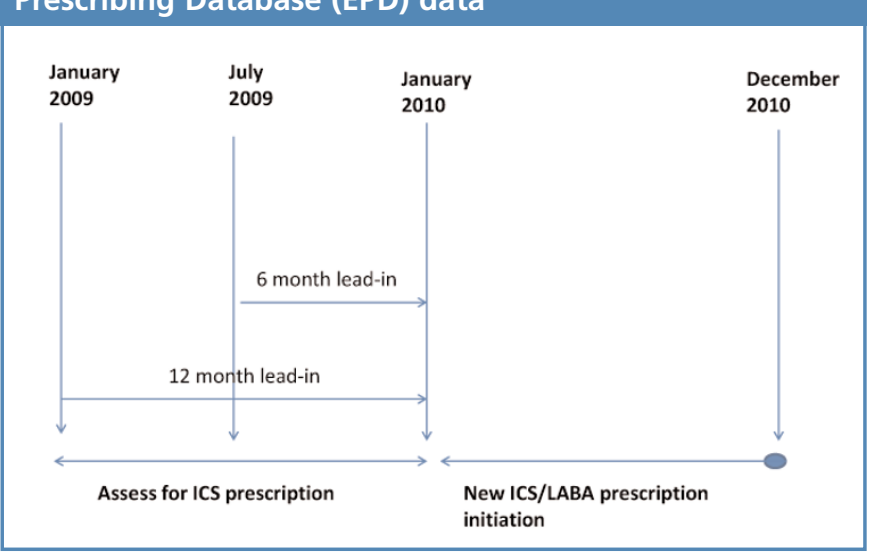

study period was 491,868 (42\% of all patients registered).

We examined dispensing of asthma therapy in the 12-month index period (January to December 2010) during which the initial prescription of ICS/LABA was dispensed, along with dispensing in either a six-month or a 12-month lead-in period in 2009 (Figure 1). We examined all asthma drug treatment dispensed prior to ICS/LABA initiation including short-acting $\beta_{2}$-agonist (SABA), inhaled corticosteroid (ICS), oral corticosteroid (OCS), leukotriene receptor antagonist (LTRA) and antibiotic use, as well as prescription filling in the preceding six months.

To validate our EPD data further, practice pharmacists overseen by HSC Medicines Management Pharmacists performed chart audits. As part of their ongoing review of primary care prescribing, they examined new prescriptions of ICS/LABA from $10 \mathrm{GP}$ practices in patients aged 5-35 years with a diagnosis of asthma. Although drawn from all five Health and Social Care Trusts in Northern Ireland, these practices were not strictly randomly selected. Within each practice, all charts which fulfilled the selection criteria were included in the audit up to a maximum of 20 (or, in one practice, 30).

Data analysis was performed using IBM SPSS Statistics, Version 19. This work was carried out as an audit of prescribing practice against predetermined standards of care (BTS/SIGN guidelines) in Northern Ireland so ethical approval was not required.

\section{Results}

During the index year 42,665 patients had two or more prescriptions for any asthma drug from BNF categories 3.1, 3.2, 3.3 dispensed, with $12,989(30 \%)$ receiving ICS/LABA. Of these, 3,953 patients (30\%) received new ICS/LABA prescriptions (no ICS/LABA in the index year or in the six-month lead-in period), with 2,640 (67\%, $95 \% \mathrm{Cl} 65 \%$ to $68 \%$ ) having no previous prescription for ICS noted in the index year or lead-in period. When the lead-in period was extended to 12 months, $52 \%$ (95\% CI 50\% to 54\%) had no ICS dispensed in the index year or during the lead-in period. Using a threshold of $>95 \%$ for all linked prescription capture resulted in a smaller sample size but demonstrated identical figures for inappropriate ICS/LABA prescribing (data not shown).

ICS/LABA was prescribed inappropriately in $41 \%$ of patients from 


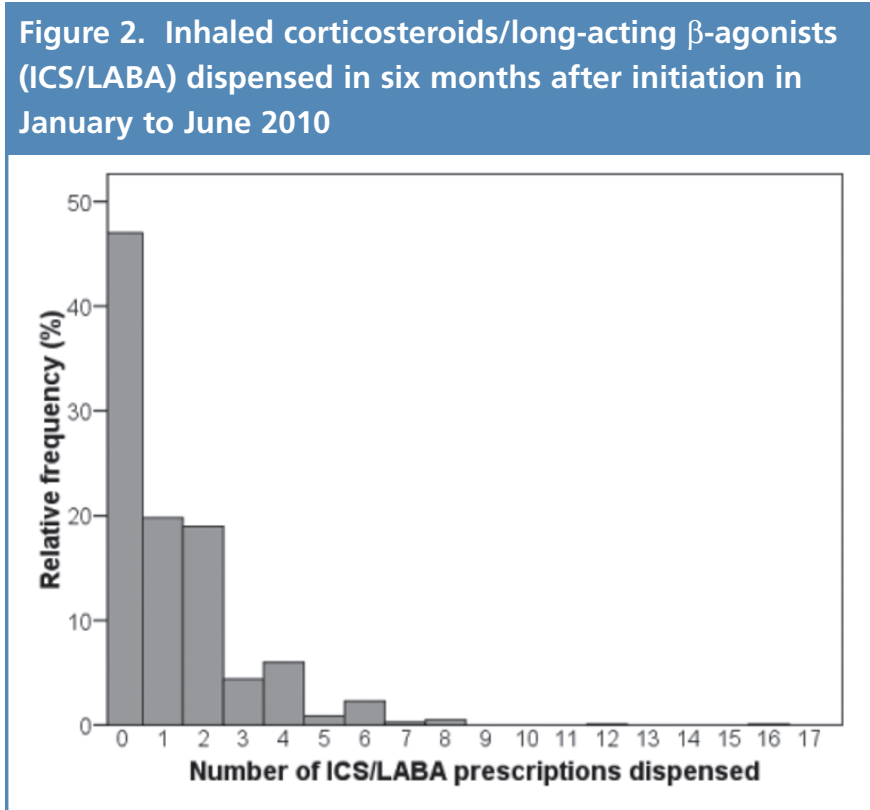

Table 1. Audit of GP practices

\begin{tabular}{|c|c|c|c|c|c|}
\hline \multicolumn{3}{|c|}{ Practice demographics } & \multicolumn{3}{|c|}{ Audit results } \\
\hline $\begin{array}{l}\text { Practice } \\
\text { ID }\end{array}$ & $\begin{array}{l}\text { List } \\
\text { size }\end{array}$ & $\begin{array}{l}\text { Number } \\
\text { on } \\
\text { asthma } \\
\text { register }\end{array}$ & $\begin{array}{l}\text { Sample } \\
\text { size }\end{array}$ & $\begin{array}{l}\% \text { on } \\
\text { asthma } \\
\text { register }\end{array}$ & $\begin{array}{l}\text { No } \\
\text { previous ICS } \\
\text { use in } 12 \\
\text { months before } \\
\text { combination } \\
\text { inhaler }\end{array}$ \\
\hline 1 & 7,027 & 423 & 20 & $95 \%$ & $45 \%$ \\
\hline 2 & 10,193 & 519 & 20 & $100 \%$ & $30 \%$ \\
\hline 3 & 5,100 & 360 & 16 & $69 \%$ & $44 \%$ \\
\hline 4 & 6,800 & 388 & 19 & $95 \%$ & $26 \%$ \\
\hline 5 & 11,833 & 810 & 30 & $90 \%$ & $7 \%$ \\
\hline 6 & 6,411 & 404 & 18 & $83 \%$ & $11 \%$ \\
\hline 7 & 8,705 & 583 & 18 & $94 \%$ & $22 \%$ \\
\hline 8 & 10,750 & 779 & 20 & $100 \%$ & $40 \%$ \\
\hline 9 & 7,800 & 494 & 7 & $71 \%$ & $71 \%$ \\
\hline 10 & 2,660 & 142 & 5 & $80 \%$ & $40 \%$ \\
\hline
\end{tabular}

January to March, $26 \%$ from April to June, $18 \%$ from July to September, and $15 \%$ from October to December.

In the six months prior to ICS/LABA being first dispensed, 1,267 (48\%) had no record of a prescription dispensed for SABA, OCS, LTRA, or antibiotic therapy while $723(27 \%)$ received a SABA, 132 $(5 \%)$ received a course of steroids, $701(27 \%)$ received an antibiotic, and $128(5 \%)$ received an LTRA.

Symbicort ${ }^{\circledR}$ (budesonide/formoterol) was initiated in 1,491 (56\%) of the 2,640 patients, closely followed by Seretide ${ }^{\circledast}$ (flixotide/ salmeterol) in 1,132 (43\%), with Fostair ${ }^{\circledR}$ (beclomethasone/ formoterol) initiated in 17 patients (1\%). Symbicort ${ }^{\circledast}$ was most frequently initiated in the $200 / 6 \mu \mathrm{g}$ dose (36\%), followed by $100 / 6 \mu \mathrm{g}$ $(18 \%)$ and $400 / 12 \mu \mathrm{g}(2 \%)$. Seretide ${ }^{\oplus}$ was most frequently initiated as the Evohaler with $125 / 25 \mu \mathrm{g}(14 \%)$ followed by $250 / 25 \mu \mathrm{g}(9 \%)$ and $50 / 25 \mu \mathrm{g}(8 \%)$. Seretide ${ }^{\circledast} 100 \mu \mathrm{g}(6 \%)$ was the most frequently initiated form of Accuhaler followed by $250 \mu \mathrm{g}(5 \%)$ and $500 \mu \mathrm{g}$ $(1 \%)$.

Of the patients who had their first ICS/LABA inhaler dispensed between January and June 2010, 47\% received no further ICS/LABA in the six-month period following initial dispensation (Figure 2), with $39 \%$ receiving one or two further prescriptions.

The results of the chart audit of the $10 \mathrm{GP}$ practices are shown in Table 1. The proportion of charts in which a new ICS/LABA was initiated without ICS/LABA prescription in the previous 12-month period ranged from $7 \%$ to $71 \%$ across the 10 practices.

\section{Discussion}

\section{Main findings}

In this analysis of prescription data in Northern Ireland in 2010, we found widespread initiation of ICS/LABA therapy without prior regular use of ICS monotherapy, which is contrary to asthma management guidelines. ${ }^{1}$ Initiation of ICS/LABA does not appear to be driven by persistent asthma symptoms (17\% received SABA in the previous six months) or severe asthma exacerbation (5\% received oral steroids, which we use as a surrogate for acute severe asthma as it is the standard of care). In our GP chart audit, we also identified inappropriate prescribing at the practice level, consistent with the dispensing database analysis. We believe our data are consistent with widespread inappropriate initiation of ICS/LABA in Northern Ireland and that these EPD data may reflect what is actually happening in primary care across the rest of the UK.

A large proportion of inappropriate ICS/LABA prescribing occurred in the period from January to March $(41 \%)$. This could reflect the time of year and a propensity to viral infection with more prominent symptoms, but seasonal peaks in asthma also occur in other periods of the year. Increased annual asthma reviews in the early part of the year for the Quality and Outcomes Framework (QOF) may also be relevant, with increased patient contact at this time resulting in more changes in therapy. However, our data do not allow a precise explanation for this seasonal surge, but demonstrate a lack of evidence-based prescribing in primary care.

From an economic perspective, the choice of inhaler had a considerable impact on the overall cost of this prescribing practice. In Northern Ireland in 2010, $f 49$ million was spent on respiratory drugs. ICS/LABA accounted for $47 \%$ of this, amounting to just over f23 million of this entire drug spend. ${ }^{3}$ In fact, combination inhalers rank in the top five most costly drugs to the NHS across all regions of the UK. In England, Seretide 250 Evohaler has ranked as the most expensive drug in recent years, with a spend of over $\mathrm{f} 170$ million in 2011 and, across the rest of the UK, two of the most common forms of ICS/LABA were in the top five most costly drugs. ${ }^{4 \cdot}$ ${ }^{6}$ Interestingly, 9\% of patients were prescribed Seretide ${ }^{\circledR} 250$ Evohaler while $36 \%$ were prescribed and dispensed the next most costly drug (Symbicort ${ }^{\circledR} 200 / 6 \mu \mathrm{g}$ ), both of which are among the top five most expensive drugs to the NHS. Fewer than $1 \%$ were dispensed Fostair ${ }^{\otimes}$ which, at the time, was the cheapest ICS/LABA available. A considerable saving could be made based on the 
inappropriate prescribing and dispensing data from our analysis. The average cost per patient per year for ICS/LABA based on inhaler use

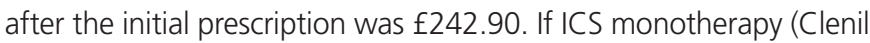
Modulite CFC Free Inhaler 50 $\mathrm{\mu g}$ ) was initiated instead of ICS/LABA, a saving of $£ 591,729$ would be achieved for this group of patients in a single year. ${ }^{3}$ Although we have shown that many patients did not receive ICS/LABA in the months after the initial prescription, we believe that, once started on inhaled combination therapy, if the patient does require a future prescription he/she is likely to continue to receive ICS/LABA. Thus, if the figure for inappropriate initiation was extrapolated to include other years and to include all patients in Northern Ireland, the economic consequences would be substantially more.

\section{Interpretation of findings in relation to previously published work}

Previous studies have examined this prescribing issue with variable results. ${ }^{7-10}$ In a UK cross-sectional observational study using data from the General Practice Research Database (GPRD), Thomas et al. examined prescribing patterns in just over 10,000 children aged $\leq 14$ years and found that $7 \%$ of patients were prescribed ICS/LABA with no asthma controller therapy in the previous six months. ${ }^{7}$ In the USA, a retrospective study of insurance claims reported that $55 \%$ of children aged 4-11 years were prescribed ICS/LABA (fluticasone/ salmeterol) as initial asthma controller therapy ${ }^{8}$ and, in Canada, another insurance claim-based database study found that over $60 \%$ of individuals aged 16-44 years had no ICS in the 12 months prior to initiation of ICS/LABA. In this study, when looking back at 24 months of prescribing records, $50 \%$ of the cohort still had not used ICS. ${ }^{9}$ Bianchi et al., in their analysis of an Italian region's prescription database for children aged 6-17 years, found further inappropriate prescribing in asthma - particularly for those with newly diagnosed asthma - with $23 \%$ receiving ICS/LABA as first-line therapy. ${ }^{10}$ None of these studies could explain why this prescribing occurred, but concern about the use of higher doses of inhaled steroids and widespread marketing of combination inhalers may be potential drivers. Our data are consistent with other studies from outside the UK, and further analysis is required to understand the precise reasons for this prescribing practice and the cost implications for primary care.

Implications for future research, policy and practice As part of an initiative to improve asthma management in primary care and in collaboration with Medicines Management Pharmacists, our audit in $10 \mathrm{GP}$ practices showed, on a smaller scale, the same phenomenon as that identified in our database analysis - specifically, widespread initiation of ICS/LABA without prior ICS therapy in the previous 12 -month period. This audit has been incorporated into ongoing medicines management reviews in Northern Ireland in order to influence prescribing at the individual practice level. This work has encouraged the development and introduction of regional guidelines, ${ }^{11}$ which highlight the problem of inappropriate prescribing of ICS/LABA. This advocates asthma management that follows the BTS/SIGN guidelines and includes checking of adherence, inhaler technique, and prescription filling prior to stepup in asthma therapy, particularly ICS/LABA, and local auditing of prescribing practices in primary care. This approach could be adopted throughout the UK and would improve adherence to guidelines as well as bringing about substantial savings in ICS/LABA prescribing to the NHS.

\section{Strengths and limitations of this study}

There are some limitations with the analysis of large-scale prescription databases. Demographic and individual patient data are not available, so it is not feasible to comment on disease severity or other patient or disease characteristics. Incomplete prescription information, due to lack of data capture, may also be a confounding factor. However, we used practices with excellent data capture for all prescriptions linked to a valid $\mathrm{HCN}$ (>85\%) and, when we increased this threshold to $>95 \%$, the percentage of inappropriate initiation of ICS/LABA was unchanged. As discussed above, we believe the majority of this population had underlying asthma, based on age group, but cannot comment on asthma severity or indication for ICS/LABA. However, given the widespread nature of the prescription, it seems unlikely that severity was the indication to move straight to combination therapy in these patients. Another limitation is that our data are specific to prescribing practice in Northern Ireland and further detailed research needs to be replicated in other regions of the UK.

\section{Conclusions}

In summary, ICS/LABA is being prescribed and dispensed inappropriately in Northern Ireland, contrary to the advice of national asthma management guidelines. Our analysis shows that most prescriptions were initiated in the January to March period and did not appear to be driven by severe asthma exacerbation (oral steroid prescription) or worsening asthma control (SABA use). Significant reductions in ICS/LABA with associated cost savings would occur if the $\mathrm{BTS} / \mathrm{SIGN}$ prescribing guidelines were followed in primary care.

Handling editor Irem Patel
Statistical review Gopal Netuveli

Conflicts of interest The authors declare that they have no conflicts of interest in relation to this article.

Contributorship LGH, JS, GP, VL and TMCA were responsible for collating the data for this manuscript. LGH, JS, CCP, SO'N and CO'N were responsible for analysing and managing the data. All authors contributed equally to the manuscript. Funding These data were generated as a result of a related Knowledge Transfer Scheme on non-adherence in difficult asthma (HSC Knowledge Transfer Scheme RES/4321/10).

\section{References}

1. British Thoracic Society/Scottish Intercollegiate Guidelines Network. British guideline on the management of asthma - a national clinical guideline. Revised January 2012. Available from http://www.brit-thoracic.org.uk/guidelines/asthma-guidelines.aspx

2. National Institute for Health and Clinical Excellence. Inhaled corticosteroids for the treatment of chronic asthma in adults and in children aged 12 years and over. NICE Technology Appraisal Guidance 138, 2008.

3. HSC Prescription Cost Analysis for Northern Ireland 2010. http://www.hscbusiness.hscni.net/services/1806.htm

4. NHS Information Centre, Prescription Cost Analysis England, 2011. http://www.ic.nhs.uk/searchcatalogue?productid=5461\&q=title\%3a\%22prescriptio $\mathrm{n}+$ cost+analysis\%22\&sort=Relevance\&size=10\&page=1\#top

5. Welsh Government, Prescription Cost Analysis Wales, 2011. http://wales.gov.uk/topics/statistics/headlines/health2012/1203281/?lang=en

6. Information Services Division, Prescription Cost Analysis Scotland, 2011. 
http://www.isdscotland.org/Health-Topics/Prescribing-and-Medicines/CommunityDispensing/Prescription-Cost-Analysis/

7. Thomas M, Murray-Thomas T, Fan T, Williams T, Taylor, S. Prescribing patterns of asthma controller therapy for children in UK primary care: a cross-sectional observational study. BMC Pulm Med 2010;10:29.

http://dx.doi.org/10.1186/1471-2466-10-29

8. Friedman HS, Eid NS, Crespi S, Wilcox TK, Reardon G. Retrospective claims study of fluticasone propionate/salmeterol fixed-dose combination use as initial asthma controller therapy in children despite guideline recommendations. Clin Ther 2009;31:1056-63. http://dx.doi.org/10.1016/j.clinthera.2009.05.008

9. Breton MC, Lelorier J, Forget A, Blais L. Use of combination therapy in asthma: are they prescribed according to guidelines. Respir Med 2007;101:1916-23. http://dx.doi.org/10.1016/j.rmed.2007.04.017

10. Bianchi M, Clavenna A, Sequi $M$, et al. Anti-asthma medication prescribing to children in the Lombardy region of Italy: chronic versus new users. BMC Pulm Med 2011;11:48. http://dx.doi.org/10.1186/1471-2466-11-48

11. Health and Social Care Board. Asthma: keeping in STEP with the guidelines. Northern Ireland Medicines Management Newsletter 2012;3(4):Supplement. http://www.hscboard.hscni.net/medicinesmanagement/Medicines\%20Management \%20Newsletter/Volume \%2003/004\%20lssue \%204\%20-\%20Special\%20 Supplement.pdf

Available online at http://www.thepcrj.org 